\title{
Economic Growth And Capital Market Development In Nigeria An Appraisal
}

\section{Agu Bertram O.}

Department Of Banking And Finance Enugu State University Of Science And Technology, Esut Enugu, Nigeria, dragubertram@gmail.com.

\begin{abstract}
This paper appraised the responsiveness of economic growth to capital market development in Nigeria. Specifically, the study sought to, (i) determine the impact of market capitalization on Real Gross Domestic Product (RGDP) (ii) ascertain the effects of value of shares traded in the capital market on Real GDP and (iii) find out whether the total number of issues in the capital market impact on RGDP in Nigeria. The researchers adopted time series data from 1995-2016 which were drawn from Central Bank of Nigeria Statistical bulletin and stock exchange review reports. The analysis of data was done using descriptive statistics and ordinary least square (OLS) regression Technique. The result of the study shows that market capitalization was found to have negative relationship with Real Gross Domestic Product (GDP) in Nigeria. The study also reveals that there is limited contribution of the capital market to the development of industrial sector. The study recommended that there should be improvement on the declining market capitalization by encouraging investors to invest in the sector.
\end{abstract}

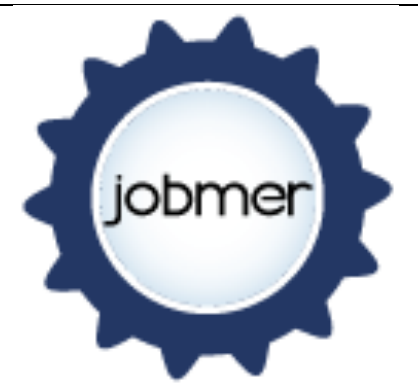

Journal of Business Management and Economic Research

Vol.2, Issue.4, 2018 pp. $27-38$

Doi: 10.29226/TR1001.2018.28

Keywords: Capital Market, Value of Shares, GDP, Number of stock issued and Ordinary Least Square (OLS) 


\section{INTRODUCTION}

Globally, the important of capital market as an efficient channel of financial intermediation has been recognized by the researchers and policy makers as a primary determinant of economic growth of any nation (Oluwatosin, Adekanye and Yusuf, 2013). The capital market is the segment of the financial system which facilitates the channeling of long-term funds from surplus to deficit economic units thereby stimulating capital formation and socio-economic development.

The introduction of Structural Adjustment Program (SAP) in Nigeria resulted in significant growth of the financial sector and the privatization exercise which exposed investors and companies to the significance of the stock market. The liberalization of capital market led tremendous changes with respect to volume, number of deals and value of securities traded as well as the number of securities listed in the market, yet there are concerns on its impact at the macro-economic level.

Again the capital market was instrumental to the initial twenty-five Banks that were able to meet the minimum capital requirement of N25 billion during the banking sector consolidation in 2005. The stock market has helped government and corporate entities to raise long term capital for financing new projects, and expanding and modernizing industrial/commercial concerns (Oladipo and Tunde, 2013)

Oluwatosin, Adekanye and Yusuf (2013) infer that the capital market has undergone tremendous reforms in recent years. Among these is the introduction of Central Securities Clearing System (CSCS), an automated clearing, settlement and delivery system aimed at easing transactions and fostering investors' confidence in the market. Equally important is the linking of performance information on the Nigerian Stock Exchange to Reuters International System in order to disseminate relevant market information to subscribers. However, poorly functioning capital markets typically are illiquid and expensive which deters foreign investors. Illiquid and high transactions costs also hinder the capital raising efforts of lager domestic enterprises which pushed them to foreign markets.

The capital market effectively started operations in Nigeria on 5th June, 1961 under the provision of the Lagos Stock Exchange Act 1961, which transformed into the Nigerian Stock Exchange in December 1977 as a result of the review of the Nigerian financial system (CBN, 2007). The Securities and Exchange Commission (SEC) was established in 1979 through the SEC Act 1979, to regulate the capital market, but it commenced actual operation in 1980. It took over regulatory functions from Capital Issues Commission, which was established in 1973. Since then, various forms of financial instruments have been issued in the capital market by new and existing business to finance product development, new projects or general business expansion.

The Nigerian Stock Exchange provides the essential facilities for companies and government to raise money for business expansion and development projects through investors who own shares in corporations for the ultimate benefit of the economy. The Nigerian Stock Exchange was also established to increase the rate of capital formation in the economy, to bring currency in circulation in banking sector and to enhance the effectiveness of the country's monetary policy and to expand the market (NSE, 2006).

It is obvious therefore that finance is an essential ingredient in the stimulation of economic growth and development. In the light of the foregoing therefore, this research study focuses on the investigation of the responsiveness of economic growth to capital market development of Nigerian, 1995-2016. 


\section{Statement of the Problem}

The impact of the global financial crisis affected the exchange performance in Nigeria. In the same vein, the number of deals increased from 10,199 in 1981 to peak at 49,029 in 1992, before falling to 40,398 in 1993 . It later rose significantly to $3,535,631$ in 2008 , and declined by -50.8 per cent to $1,739,365$ in 2009 . The growth in the market also manifested in the phenomenal increase in market capitalization, from N5.0 billion to N7,030.8 billion in 2009, over ten-fold jump. The phenomenal growth notwithstanding, the market capitalization represents only 28.0 per cent of the GDP, compared with 167.1 per cent for South Africa, 50.7 per cent for Zimbabwe and 130.0 per cent for Malaysia, (CBN, 2007). This shows that the potentials and prospects for growth in the Nigerian market are bright.

The linkage between capital market performance and economic growth has often generated strong controversy among analysts based on their study of developed and emerging markets (Kolapo and Adaramola, 2012). The determination of the growth of an economy depends on how efficiently the capital market performs its allocative function of capital. As the stock market mobilizes savings, concurrently it allocates a larger proportion of it to the firms with relatively high prospects as indicated by its rate of returns and level of risks (Alile, 1997).

Nevertheless, there is abundant evidence that most Nigerian businesses lack medium and long -term capital. The business sector has depended mainly on short-term financing such as overdrafts to finance even long-term investment. Based on the maturity matching concept, such financing is risky. All such firms need to raise an appropriate mix of short- and long-term capital which in other will have an impact to the economy (Edame and Okoro, 2013). In the light of the above mentioned facts, the study aimed at appraising the responsiveness of economic growth to capital market development of Nigerian (1995-2016).

\section{Objectives of the Study}

The broad objective of this study is an appraisal of the effect of capital market on the growth of Nigerian economy. The specific objectives include to:

- Determine the effect of market capitalization on real Gross Domestic Product (GDP).

- Ascertain the effects of value of shares traded in the capital market on real GDP.

- Determine whether the total number of issues in the capital market impact on real GDP.

\section{Research Questions}

What are the effects of market capitalization on real GDP?

$>$ To what extent has the value of shares traded in the capital market affects real GDP?

$>$ To what extent has total number of issues in the capital market impact on real GDP?

\section{REVIEW OF RELATED LITERATURE}

\section{Conceptual Framework}

\section{Concept of Capital Market}

Capital market is defined as the market where medium and long term finance are bought and sold (Akingbohugo, 2006). Capital market offers varieties of financial instrument that enable economic agents to pool, price and exchange risk. Through assets with attractive yields, liquidity and risk characteristics, it encourages savings in financial form. This is very essential for government and other institutions in need of long term funds (Nwankwo, 2011). According to Al-Faki (2009), the capital market is a network of specialized financial institutions, series of 
mechanisms, processes and infrastructure that, in various ways, facilitate the bringing together of suppliers and users of medium to long term capital for investment in socio-economic developmental projects". Emekekwue (2016) stated that capital market provides facilities for transfer of medium and long term funds to various economic units.

\section{Historical Development of the Nigerian Capital Market}

The activities and trading in this market is managed by the Nigerian Stock Exchange (NSE) which evolved in 1977 from the Lagos Stock Exchange, established in June 5, 1961. As at end of 2009, there were ten trading floors of the NSE. The Lagos branch serves as the head office of the exchange, Enugu, Ibadan, Onitsha, Kaduna, Kano, Port Harcourt, Yola, Benin and Abuja were the other branches of the exchange (Oladipo and Tunde, 2013).

Each branch has a trading floor, which creates opportunities for buying and selling of securities. Other than these, there are institutions such as the Securities and Exchange Commission (SEC), which is the regulatory authorities and was established in 1979, issuing houses, Investment Advisers, Portfolio Managers, Investment and Securities Tribunal (IST), the stock broking firms, registrars and other operators. The interactions among these players influence the width and depth of the market. Prior to 1980s, trading in the market was weak, attributable mainly to low level of information dissemination and awareness.

However, with the level of computerization and availability of corporate information, the market becomes more efficient with major indicators reflecting remarkable growth. Since the 1980s, most of the market indicators including all-share value index, number of deals, market capitalization, total value of shares traded and turnover ratio have recorded significant increases. (Oladipo and Tunde, 2013).

The improvements could be attributed to the establishment of the Second-tier Securities Market (SSM) in 1985; the deregulation of interest rates in 1987, the privatization programme of government owned companies, enhancement in market infrastructure and requirements, innovations; as well as the banking sector reform. These developments have culminated in unprecedented growth of both the primary and secondary markets (Ozurumba and Chigbu, 2013).Some of the major securities traded on the exchange during the period under review included, government development stocks, industrial loans/preference shares and equities. From 100.00 in 1984, the all-share value index on the exchange rose to 57,990.22 in 2007, but declined by -64.1 per cent to 20.827 .17 in 2009 as some quoted banks were involved in merger/acquisitions in the recapitalization exercise in the banking sector, while those that were unsuccessful were de-listed from the exchange. . The growth and development of the capital market in Nigeria can be traced to 1946 with the floating of N600,000 (more than 300,000 pounds sterling) worth of government stocks. However, an organized market for the secondary trading of issued stocks was lacking. In 1959, following the establishment of the Central Bank of Nigeria $(\mathrm{CBN})$ a year earlier, a N4million (2million pounds sterling). Federal government of Nigeria development loan stock was issued in line with its role of fostering economic and financial development. The stock market has helped government and corporate entities to raise long term capital for financing new projects, and expanding and modernizing industrial/commercial concerns (Nwankwo, 1991)

\section{Market Capitalization}

MCAP or market cap/ market capitalization represents the aggregate value of a company or stock. It is obtained by multiplying the number of shares outstanding by their current price per share. For example, if XYZ company has $15,000,000$ shares outstanding and a share price of $\$ 20$ per share then the market capitalization is $15,000,000 \times \$ 20=\$ 300,000,000$. Generally, the U.S. 
market recognizes three market cap divisions: large cap (usually $\$ 5$ billion and above), mid cap (usually $\$ 1$ billion to $\$ 5$ billion), and small cap (usually less than $\$ 1$ billion), although the cutoffs between the categories are not precise or fixed. Found at http://www.investorwords.com/2969/market_capitalization.html\#ixzz5757L7GhJ

Market capitalization is one of the best measures of a company's size. Also known as market cap, market capitalization is the total market value of a company's outstanding shares of stock. For example, you may have heard Apple referred to as "the most valuable company in the world." That's because Apple currently has the highest market cap of any publicly traded company.

A company can issue new shares of stock to increase its market capitalization. Note that a stock split won't affect a company's market capitalization, even though it will increase the total shares outstanding. The reason is that when stocks are split, their individual prices are split by the same proportion. If a company has 30 million shares outstanding worth $\$ 10$ each, after a 2-for-1 split, it will have 60 million shares outstanding worth $\$ 5$ each. Either way, the product of that company's shares outstanding multiplied by its stock price will be the same, or so its market cap will not change.

\section{ECONOMIC GROWTH}

Economic growth means an increase in the capacity of an economy to produce goods and services, compared from one period of time to another. Economic growth is a process by which a nation wealth increases over time. The most widely used measures of economic growth is the rate of growth in a country's total output of goods and services gauged by the gross domestic product (GDP)

Economic growth can also be refers to as the increase of per capita gross domestic product (GDP) or other measures of aggregate income, typically reported as the annual rate of change in the real GDP. Economic growth is primarily driven by improvement in productivity, which involves producing more goods and services with the same inputs of labour, capital, energy and materials (Gbadamosi, 2017)

\section{The Roles of the Nigerian Capital Market}

Emekekwue (2009) categorized the role of the Nigerian Capital Market into three major headings namely:

- The Pooling Function.

- Facilitating Capital Formation.

- Risk Reduction Function

\section{The Pooling Function}

The capital market through its agencies like banks, insurance companies etc pools the resources of the economic surplus units and channel them to economic deficit units who will then put such funds to productive use. Ugwuanyi (2013) states that capital market provides access to finance for new and small companies and encourage institutional development in facilitating the setting up of Nigeria's domestic funds, foreign funds and venture capital funds.

\section{Facilitating Capital Formation}

Emekekwue (2009) stated that in disbursing the resources that they have pooled together, the capital market through its agencies ensures that the funds are given to those economic units that will utilize the funds judiciously so as to increase their capital stock. To that effect, the 
economic units receiving the pooled resources have increased their capital stock hence financial institutions facilitate capital formation.

\section{Risk Reduction Function}

Through its resource pooling (savings) function acting as conduit pipe to channel those resources to savings deficit economic units, the financial institutions diversify ways for existing resources to meet with competing needs. This diversification process of resources reduces risk inherent in investment. With all the above enumerated roles of the Nigerian capital market however, attainment of such goals is not feasible without the pivotal role of the Nigerian Stock Exchange. The Nigerian capital market without the Nigerian stock exchange is like an automobile without fuel to propel it.

\section{Theoretical Framework}

The study adopted the Growth Theories as propounded by Adam Smith (1776), - The theory enquired into the Nature and causes of the Wealth of Nations which did not give a well-defined meaning of theory of development but the leading theme has been that of economic growth.

The Smith theory believes that if individuals are left free to seek for the maximization of their own personal wealth, the aggregate wealth of the economy will also be maximized. This theory assumes that institutional, political and natural factor remain unchanged. For economic growth to take place the main factor is labour, with division of labour there will be an improvement into the productivity of labour. This is because there will be an increase in the skill of every worker. Our interest is capital accumulation which is the pride of place in the Smith theory; he regarded capital accumulation as a necessary condition for economic growth and development. It is belief that the higher the rate of savings in the economy the more the investment that will be made (Adam Smith, 1776).

\section{Empirical Review}

The first comprehensive study on the relationship between capital market development and economic growth, according to Levine (1997), was undertaken by the World Bank Research Group. They investigated the compatibility of stock market development with financial intermediaries and economic growth and concluded that stock market development is positively correlated with the development of financial intermediaries and long term economic growth. Obstfeld (2015) identifies risk diversification, through internationally integrated stock markets, as another vehicle through which stock markets can raise resources and affect growth.

In Romania, Brasoveanu, et al (2015) studies the correlation between capital market development and economic growth for the period 2000 to 2016. The result indicates that capital market development is positively correlated with economic growth by way of feed-beck effect. Bolbol, Fatheldine and Omaran (2015), indicates that capital market development has contributed to the economic growth of Egypt.

Adamu and Sanni (2015), examine the roles of the stock market on Nigeria's economic growth, using Granger-causality test and regression analysis. They discovered a one-way causality between GDP growth and market turnover. They also observed a positive and significant relationship between GPD growth and market turnover ratios. The authors advised that government should encourage the development of capital market since it has a positive effect on economic growth.

Kareem, Sanni, Raheem, and Bakare (2013) employed multiple regressions to estimate the functional relationship between money supply, inflation, interest rate, exchange rate and stock

prices. Their study revealed that the relationship between stock prices and the macroeconomic 
variables are consistent with theoretical postulation and empirical findings in some countries. Though, they found that the relationship between stock prices and inflation does not agree with some other works done outside Nigeria.

\section{METHODOLOGY}

\section{Research Design:}

The study adopted an ex-post facto research design. Ex-post facto is mostly used in a study where it is not possible or acceptable to manipulate the characteristics of the variables under study. The use of descriptive statistics is necessary as the data set is entirely quantitative and requires the use of analytical and statistical techniques. In view of the above, this study adopted Augmented Dickey Fuller (ADF) test for the unit root test in order to attain stationarity. The Engle- Granger and Johansen's Co integration was conducted to ascertain if there is a long run relationship among the variables. The Parsimonious Error Correction modeling was adopted to correct for shocks and innovations, decomposing them into short run and long run impacts.

\section{Nature and Sources of Data}

The data for the work is annualized time series which consist of mainly secondary data. The study covers 1995 to 2016. The data are accessed from the Central Bank of Nigeria databank and statistical Bulletin various issues. Nigerian Stock Exchange (NSE) fact books, Security and Exchange Commission (SEC) market Bulletins and relevant journals. The choice of the period 1995 to 2016 was informed by the availability of data in the form detailed enough to allow for robust analyses

\section{Model Specification}

The model of this study is based on the Classical Linear Regression Model of Brooks (2014). An econometric analysis of which Economic Growth proxies RGDP is the dependent variable while the independent/ explanatory variables are market capitalization, value of shares traded and total new issues. The model is shown as follows;

$Y=\beta 0+\beta 1 X 1+\beta 2 X 2+\beta 3 X 3$------ $\beta n X n+U t$--------------- 3.1

Where;

$\mathrm{Y}=$ Dependent variable

$\mathrm{X} 1, \mathrm{X} 2, \mathrm{X} 3--------------\mathrm{X} \mathbf{n}=$ the explanatory or independent variables

$\mathrm{B} 1, \beta 2, \beta 3-------------\beta n=$ the coefficient of the parameter estimate or the slope

$\mathrm{Ut}=$ Error or disturbance term

In relating this to the study;

RGDP $=f($ MCAP $, T N I, V L T)$ 3.2

Relating it in econometric form and the variables log linearised, it will appear thus;

LRGDP $=\beta 0+\beta 1$ LnMACP + $\beta 2$ LnTNI + $\beta 3$ LnVTS-------------Ut ------------ 3.3

Where;

LnRGDP = Real Gross Domestic Product

LnMCAP = Market Capitalization

LnTNI = Total New Issues

LnVTS = Value of Transactions (Government and Industrial securities) 


$$
\begin{array}{ll}
\mathrm{Ut} & =\text { Disturbance } / \text { Error term } \\
\beta & =\text { Intercept }
\end{array}
$$

$\beta 1-\beta 3=$ Coefficient of the Independent Variables.

A priory expectation: It is expected that $\beta 1-\beta 3>0$

Note: All variables are in their natural logarithm form

\section{PRESENTATION DATA AND ANALYSIS}

\section{Presentation of Data}

Table 4.1 shows the GDP, Market Capitalization, Total New Issue, Value of Transactions in Nigeria from ( 1995-2016)

\begin{tabular}{|l|l|l|l|l|}
\hline Year & GDP & MACP & T N I & VTS \\
\hline 1995 & 267.37 & 16.3 & 67.37 & 3.23 \\
\hline 1996 & 265.38 & 23.1 & 69.38 & 2.24 \\
\hline 1997 & 271.37 & 31.2 & 33.06 & 49 \\
\hline 1998 & 374.83 & 47.5 & 26.36 & 80 \\
\hline 1999 & 275.45 & 66.3 & 21.61 & .99 \\
\hline 2000 & 281.41 & 180.4 & 44.25 & 1.84 \\
\hline 2001 & 293.75 & 285.8 & 58.58 & 6.98 \\
2002 & 302.02 & 281.9 & 108.75 & 10.33 \\
2003 & 310.89 & 262.6 & 150.18 & 13.57 \\
\hline 2004 & 312.18 & 300.0 & 120.38 & 14.07 \\
\hline 2005 & 329.18 & 472.3 & 172.08 & 28.15 \\
\hline 2006 & 356.99 & 662.5 & 371.98 & 57.68 \\
\hline 2007 & 433.21 & 764.9 & 612.84 & 58.90 \\
\hline 2008 & 477.53 & $1,359.3$ & 180.10 & 113.80 \\
\hline 2009 & 527.58 & $1,925.9$ & 195.40 & 223.90 \\
\hline 2010 & 561.93 & $2,900.1$ & 552.80 & 254.70 \\
\hline 2011 & 595.82 & $5,120.9$ & 707.40 & 468.60 \\
\hline 2012 & 634.66 & $13,294.6$ & 1935.08 & 2083.42 \\
\hline 2013 & 672.21 & $9,563.0$ & 1509.23 & 2375.61 \\
\hline 2014 & 717.00 & $7,030.8$ & 700.34 & 684.04 \\
\hline 2015 & 776.30 & $11,200.0$ & 1428.25 & 787.58 \\
\hline 2016 & 656.34 & $10,790.2$ & 1902.3 & 704.78 \\
\hline
\end{tabular}

Sources: CBN Statistical and Capital Market Bulletin Various Issues, 2017 


\section{Data Analysis and Discussion of Results}

\section{ADF Unit Root Test:}

Table 4.2: Result of Unit Test Analysis

\begin{tabular}{|l|l|l|l|l|l|}
\hline S/N & Variables & ADF t-stat & $5 \%$ critical value & $\begin{array}{l}\text { Order of } \\
\text { Integration }\end{array}$ & Trend \\
\hline 1 & GDP & -8.307644 & -2.307644 & $1(1)$ & With intercept \\
2 & MACP & -3.253225 & -2.957110 & $1(1)$ & With intercept \\
3 & TNI & -5.363889 & -2.957110 & $1(1)$ & With intercept \\
4 & VTS & -3.457620 & -2.960411 & $1(1)$ & With intercept \\
\hline
\end{tabular}

Source: E-view 9 computation

Table 4.2 shows the presentation of ADF Unit root test of stationality of the time series variables. The result shows that all the variables are 1(1) order of integration, where the absolute values of the t-test exceeded the $5 \%$ values

Table 4.3: Result of Johansen Co-integration

$$
\text { Series: } \quad \text { GDP, MACP, TNI, VTS }
$$

\begin{tabular}{|l|l|l|l|l|}
\hline \multicolumn{5}{|c|}{ Lags interval (in first differences): 1 to 1 } \\
\hline Hypothesized & & Trace & 0.05 & \\
\hline No. of CE(s) & Eigen value & Statistic & Critical Value & Prob $^{* *}$ \\
None* & 0.702716 & 88.87634 & 69.81889 & 0.0007 \\
At most 1* & 0.541468 & 51.27122 & 47.85613 & 0.0231 \\
A most 2 & 0.353137 & 27.09972 & 29.79707 & $0-0992$ \\
At most 3 & 0.237142 & 13.59546 & 15.49471 & 0.0947 \\
\hline
\end{tabular}

Trace test indicates 2 co-integrating eqn. (s) at 0.05 level of significance

Table 4.3 was used to estimate the Johansen co-integration to establish a long run relationship of the variables. The result indicates the presence of two (2) co- integrating equations at $5 \%$ level of significance. The trace statistic values of 88.87 and 51.27 exceed the 5\% critical values of 69.81 and 47.85 which show that co-integration exists.

\section{Error correlation model}


Table 4.4: Result of Error Correlation Modeling

Dependent Variables: (GDP)

Method: Least Squares

Date: 20/02/2018

Sample (adjusted): 19952016

Included observations: 30 after adjustments

\begin{tabular}{lcccc} 
Variables & Coefficient & Std.Error & t-Statistic & Prob. \\
\hline C & -0.061247 & 0.533758 & -0.114747 & 0.9095 \\
D(MACP) & -2.380328 & $1-534956$ & -1.550747 & 0.1331 \\
D(TNI) & -1.681851 & 4.326397 & -0.388742 & 0.7006 \\
D(VTS) & 0.112023 & 2.522207 & 0.044415 & 0.9649 \\
ECM(-1) & -0.840410 & 0.192910 & -4.356477 & 0.0002 \\
R-Squared & 0.437049 & Mean dependent var & -0.028437 \\
Adjusted R-square & 0.328789 & S.D. dependent var & 3.675407 \\
S.E. of regression & 3.011167 & Akaike info criterion & 5.209893 \\
Sum squared resid & 235.7452 & Schwarz criterion & 5.484718 \\
Log likelihood & -77.35829 & Hannan- Quinn criter & 5.300990 \\
F-statistic & 4.037041 & Durbin-Watson stat & 2.023053 \\
Prob(F-static) & 0.007623 & & \\
\hline
\end{tabular}

Table 4.4 presents the result of the error correction model analysis. The F-statistic indicates that all the explanatory variables are jointly significant in determining the dependent variables, with the probability of the F- ratio that falls below 5 percent (0.05). The coefficients for the individual t-statistic indicate that all our variables of focus; Gross domestic Product (GDP), Market Capitalization (MACP), Total New Issues (TNI) Value of Transactions (VTS) are statistically significant at 5 percent level of significance, since their $p$ value is less than 0.05 .

The model is dynamic since the ECM coefficient is well behaved. It is negative, but it is statistically significant. This indicates that the speed of adjustment from the short time to the long run equilibrium is only $84.04 \%$

\section{SUMMARY OF FINDINGS, CONCLUSION AND RECOMMENDATIONS}

\section{Summary of Findings}

The study examined the responsiveness of economic growth to capital market development of Nigeria between 1995 and 2016. The findings of the study reveal the following:

- The market capitalization (LMCAP) was found to have a negative relationship with the real gross domestic product (LRGDP). Its significance test shows that LMCAP has an insignificant impact on RGDP.

- The LTNI has a positive relationship with RGDP. The significance test shows significant 
impact of LTNI on the RGDP. Thus, there is a significant effect of value of shares traded in the capital market on real GDP.

- The total listing of equity on government stock (TLS) has a positive relationship with the RGDP. The significance test also shows a significant impact on the RGDP. The implication of this is that the economy responds favourably to measures taken to increase TLS in the Nigerian stock exchange

\section{Conclusion}

The study appraised the responsiveness of economic growth to capital market development via market capitalization, value of transaction and total listing of equity and government stock. As it was observed market capitalization, government stock and value of transaction are important capital market variables that are capable of influencing economic growth. Hence the capital market remain one of the mainstream in every economy that has the power to influence or impact economic growth therefore the organized private sector is to invest in it. The market capitalization have not impacted significantly on the GDP while volume of transaction and total listed equities and Government stock have significant impact on the GDP.

\section{Recommendation}

In order for the Nigeria capital market to be pivotal force in Nigeria economic growth and development, the following recommendations are put forward.

1. There should be an improvement on the declining market capitalization by encouraging more foreign investors to participate in the market, maintain state of the art technology like automated trading and settlement practice, electronic fund clearance and eliminate physical transfer of shares.

2. There is also need to restore confidence to the market by regulatory authorities through ensuring transparency and fair trading transaction and dealing in the stock exchange. It must also address the reported case of abuse and sharp practices by some companies in the market.

3. Since the total listing is significant at $5 \%$ level of significance but still far compared to other exchange like South African and Egypt, there should be increase in the total member listed companies to ensure stable macroeconomic environment in order to encourage foreign multinational companies (MNCs) or their subsidiaries to be listed on the Nigerian stock exchange, relax the listing requirements to the first tier market and ensure tax rationalization in the capital market to encourage quotation and public interest in shareholdings.

\section{REFERENCES}

AL-faki, M. (2009). The Nigerian capital market and socio-economic development. A pape presented at the 4th distinguished Faculty of Social Science, Public Lectures, University of Benin, 9-16

Alile, H. (1997). Government Must Divest" The Business Concord of Nigeria. 2nd December Akingboungbe, S. S. (1996). The Role of the Financial System in the Development of the Nigerian Economy. Paper presented at a workshop organized by Centre for Africa Lagal And Development Studies.

Anyanwaokoro M. (2008). Theory and Policy of Money and Banking, Enugu Nigeria: Hosanna Publications

Bolbol, A, Fatheldin A. and Omran M (2015). Financial Development Structure and economic 
Growth The case of Egypt 1974-2012" Research in International Business Finance 19(1) 171- 194

CBN Publication (2004 - 2008). Annual Reports and Statement of Accounts. Abuja.

Edame, G. E. and Okoro, U. (2013). The Impact of Capital Market on Economic Growth in Nigeria. Journal of Poverty, Investment and Development - An Open Access International Journal, $1(5)$

Elumide, J. and Asaolu, M. (2009). Stock Market Capitalisation of Interest Rate in Nigeria: time series Analysis. Euro Journal Publishing Inc.

Ekezie, E. S. (2012). The Elements of Banking: Money, Financial Institutes and Markets. Onitsha, Africana - Feb Publishers Limited.

Emekekwue, P. (2009). Corporate Financial Management, Enugu. African Bureau of Education Sciences.

Enisan, A. A. and A. O. Olufisayo (2009). Stock Market Development and Economic Growth:

Evidence from Seven Sub-Sahara African Countries. Journal of Economics and Business 6(1) 162171.

Oladipo, T., B and Tunde, A.B (2013). Capital Market Development and Economi Growth: Evidence from Nigeria. International Journal of Humanities and Social Scienc Invention. 2(12) 1-13

Oluwatosin, E.O ,Adekanya T. and Yusuf,S.A.(2013). Empirical Analysis of the Impact ofCapital Efficiency on Economic Growth and Development in Nigeria. Internationa Journal of Academic Research in Economics and Management Sciences. 2(6) 44-53

NSE (2009) Nigeria Stock Exchange (NSE) Fact Book 2004-2009. Lagos: The NigeriaStock Exchange. 